\title{
Travel-associated Legionnaires' disease in residents from England and Wales travelling to Corfu, Greece, August to October 2011
}

\author{
R Maini (mainirishma@gmail.com) ${ }^{1}$, F Naik ${ }^{1}$, T G Harrison ${ }^{1}$, M Mentasti $^{1}$, G Spala ${ }^{2}$, E Velonakis ${ }^{2}$, C Hadjichristodoulou ${ }^{2}$, \\ B de Jong ${ }^{3}$, A Vatopoulos ${ }^{2}$, N Phin ${ }^{1,4}$ \\ 1. Health Protection Agency (HPA), London, United Kingdom \\ 2. Hellenic Centre for Disease Control and Prevention (KEELPNO), Athens, Greece \\ 3. European Centre for Disease Prevention and Control (ECDC), Stockholm, Sweden \\ 4. Faculty of Health \& Social Care, University of Chester, Chester, United Kingdom
}

Fourteen cases of Legionnaires' disease were confirmed in residents from England and Wales with a history of travel to Corfu, Greece, in the 14 days before symptom onset. These cases were reported to the Health Protection Agency national surveillance scheme for Legionnaires' disease in residents of England and Wales between August and October 2011. In addition, one case in a Greek national and a case of non-pneumonic legionellosis in a resident from Scotland were also reported. Few cases shared the same accommodation site in Corfu during their incubation period. Epidemiological investigations and microbiological analysis of clinical and environmental samples excluded a single source but rather implicated several accommodation sites as sources of sporadic infection. Control measures have since been implemented at these accommodation sites and no further cases have been reported. This incident highlights the value of epidemiological typing and the importance of effective international response to control and prevent legionella infection.

\section{Introduction}

Legionnaires' disease (LD) is a notifiable disease across Europe. It presents as pneumonia with a case fatality rate of $10-15 \%$ [1]. LD is caused by the inhalation of aerosolised legionellae and early treatment with appropriate antibiotics may reduce the risk of complications [2]. Legionellae are widely distributed in the environment being found in all types of water systems including both natural sources, such as rivers and streams, and man-made systems, such as cooling towers, domestic water systems and spa pools [3-6]. When circumstances allow amplification of the organisms and their dispersal through aerosols to the population, such as in water systems which are not properly designed, installed and/or maintained, then there is the potential for significant numbers of people to be exposed and outbreaks to occur. Susceptible hosts include the elderly, smokers and the immunosuppressed [7].
Prompt investigation of early cases to identify the source and institute control measures is vital to prevent further cases.

Legionella pneumophila urinary antigen testing is frequently used to obtain a rapid clinical diagnosis; however, this test provides very little information about the infecting strain. Increasingly, DNA-sequence-based typing (SBT) is being used to examine isolates of L. pneumophila or, more recently, in conjunction with polymerase chain reaction (PCR) directly on clinical samples, to yield highly discriminatory epidemiological typing data which can be used to compare against environmental isolates and hence to more accurately pin-point sources of infection $[8,9]$.

This paper describes the investigation of an unexpected increase in cases from England and Wales with LD associated with travel to Corfu Island, Greece, using SBT analysis of environmental and clinical samples, and the control and prevention measures implemented as a result.

\section{Background}

In 2009, the overall rate of LD cases in Greece was $0.13 / 100,000$ population compared with a rate of $1.30 / 100,000$ population in the Netherlands and $2.63 / 100,000$ in Spain [10]. Greece is among the top 10 destinations in Europe that United Kingdom (UK) residents travel to, accounting for about $4 \%$ of the 4.7 million UK residents travelling within Europe each year; similar numbers are reported to travel to the Netherlands and Turkey [11]. Since 2000, the average number of LD cases reported to the Health Protection Agency (HPA) national surveillance scheme (for England and Wales) associated with travel to Greece is 10 per year compared with an average of 11 associated with travel to Turkey and two to the Netherlands.

Residents of England and Wales have been associated with 10 clusters in Greece since 2000, seven of which 
have been at sites on Corfu Island. This compares to 11 clusters identified in Turkey over the same period of time and one cluster identified in the Netherlands [12]. Of these clusters, only three of the 10 clusters in Greece and three of the 11 clusters in Turkey had environmental results reported to the HPA national surveillance scheme. There were no environmental results from the cluster in the Netherlands. As a consequence, no source could be confirmed in any of the clusters in the three countries, highlighting the great difficulty in identifying the source of travel-associated clusters.

On average, five cases of LD associated with travel to Corfu Island are reported annually to the HPA national surveillance scheme. The highest number of cases reported in a year has been nine cases in 2005 and 2006 (Figure 1) [12].

However in 2011, by 4 October, the HPA national surveillance scheme had identified eight cases of LD in residents of England and Wales with onset of symptoms in the 14 days following travel to Corfu. As this exceeded the annual average, and all cases had an onset of symptoms within four weeks of each other, an incident meeting was convened involving representatives from public health authorities in the UK and Greece and from the European Centre for Disease Prevention and Control (ECDC).

\section{Methods}

Information from the national enhanced surveillance questionnaire for LD [13] was collected for each case and a further trawling questionnaire was administered in order to identify any common links between the cases in either Corfu or England and Wales. Regular teleconferences were held with the Hellenic Center for Disease Control and Prevention (HCDCP), Greece, whereby data from questionnaires were shared in order to facilitate field investigations. Data exchange was also facilitated using the Epidemiological Intelligence Information System (EPIS), an international platform through which a network of experts can rapidly share data with other countries. Active case finding was undertaken by alerting the 29 member countries of the European Legionnaires' Disease Surveillance Network (ELDSNet) [14]. Both the UK and Greece enhanced casefinding activity by alerting clinicians and public health professionals through their national channels.

Environmental investigations in Corfu were undertaken by the Greek authorities. Where possible, hotel rooms and pool showers in all accommodation sites where cases reported having stayed overnight were sampled. In addition, samples were collected from public areas, including Corfu airport and fountains in Corfu city. A risk assessment was also carried out at each accommodation site.

In England and Wales, no public area was identified as a potential source of infection but Health Protection Units carried out, where possible, domestic sampling of cases' households through local environmental health departments.

Primary diagnosis of all patients was made in local microbiology laboratories using commercial L. pneumophila urinary antigen kits. Following standard practice, the local laboratories were asked to forward all clinical samples from cases to the national legionella reference laboratory in the HPA Respiratory and Systemic Infections Laboratory (RSIL) in London.

\section{FIGURE 1}

Cases of Legionnaires' disease in residents of England and Wales, with reported travel to Corfu, Greece, 2000-2011

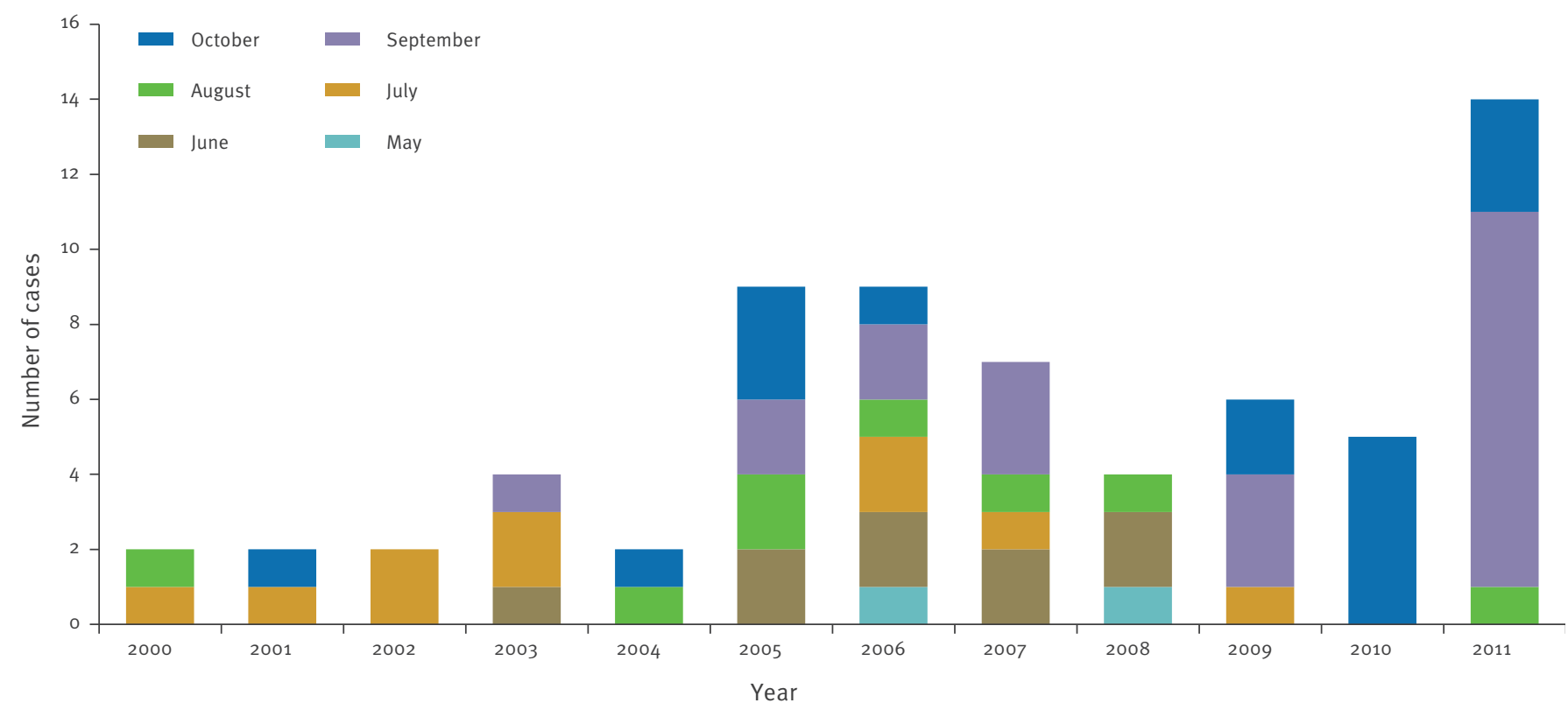


Urine samples from all cases were examined using the RSIL in-house assay which is specific for L. pneumophila serogroup 1 strains of the $\mathrm{mAb}_{3} / 1$ subgroup [15]. Sputum samples were requested for all urinary antigen positive patients for culture and any isolates obtained were characterised using monoclonal antibody (mAb) subgrouping [16] and SBT [9]. Samples which yielded a positive result in the $L$. pneumophila specific PCR but were culture-negative, were examined using nesteddirect SBT [10].

Environmental samples were cultured by standard methods [17] in either the Central Laboratory of Public Health in Vari-Attica or the Laboratory of Public Health of Thessaly, Greece. At the time of this investigation these laboratories did not have the capacity to undertake full epidemiological typing of isolates, a representative selection of positive isolates obtained were then submitted to RSIL, as the ELDSNet co-ordinating laboratory, for further characterisation by mAb subgrouping and SBT.

\section{Results}

Fourteen confirmed cases of LD were detected in residents of England and Wales; a Greek national with LD was also identified. One case of non-pneumonic legionellosis was identified in a resident from Scotland. All cases had been in Corfu in the 14 days before onset of symptoms.
The earliest date of onset of symptoms of cases from England and Wales was 2 August 2011 and, the latest date was 12 October 2011 (Figure 2). The median age of cases was 61 years (range: 39-79), and eight of the cases were male. Seven patients had known co-morbidities. All cases were hospitalised and seven cases were admitted to intensive care units; one patient required extracorporeal membrane oxygenation. One case died 27 days after onset of symptoms.

A trawling questionnaire was completed for all 14 cases from England and Wales. Thirteen of the 14 cases had stayed in tourist accommodation. The remaining case had stayed in a private villa owned by a friend. In total, 10 different accommodation sites associated with cases were identified, and the locations of these were scattered across Corfu. There were three accommodation sites where more than one case had stayed: two cases stayed at Site A (early August and late September), two cases stayed at Site D (early September and midSeptember) and three cases stayed at Site $\mathrm{H}$ (two in mid-September and one in late September): only the two cases in Site $\mathrm{H}$ stayed in accommodation at the same time. Cases did not appear to share a common airline tour company, or airport of departure or arrival in England or Wales, and no other common potential exposures were identified.

For three of the cases, domestic sampling of home residences in England and Wales was undertaken but

\section{FIGURE 2}

Cases of Legionnaires' disease in residents of England and Wales associated with travel to Corfu, Greece ${ }^{\text {, }}$, August-October $2011(n=14)$

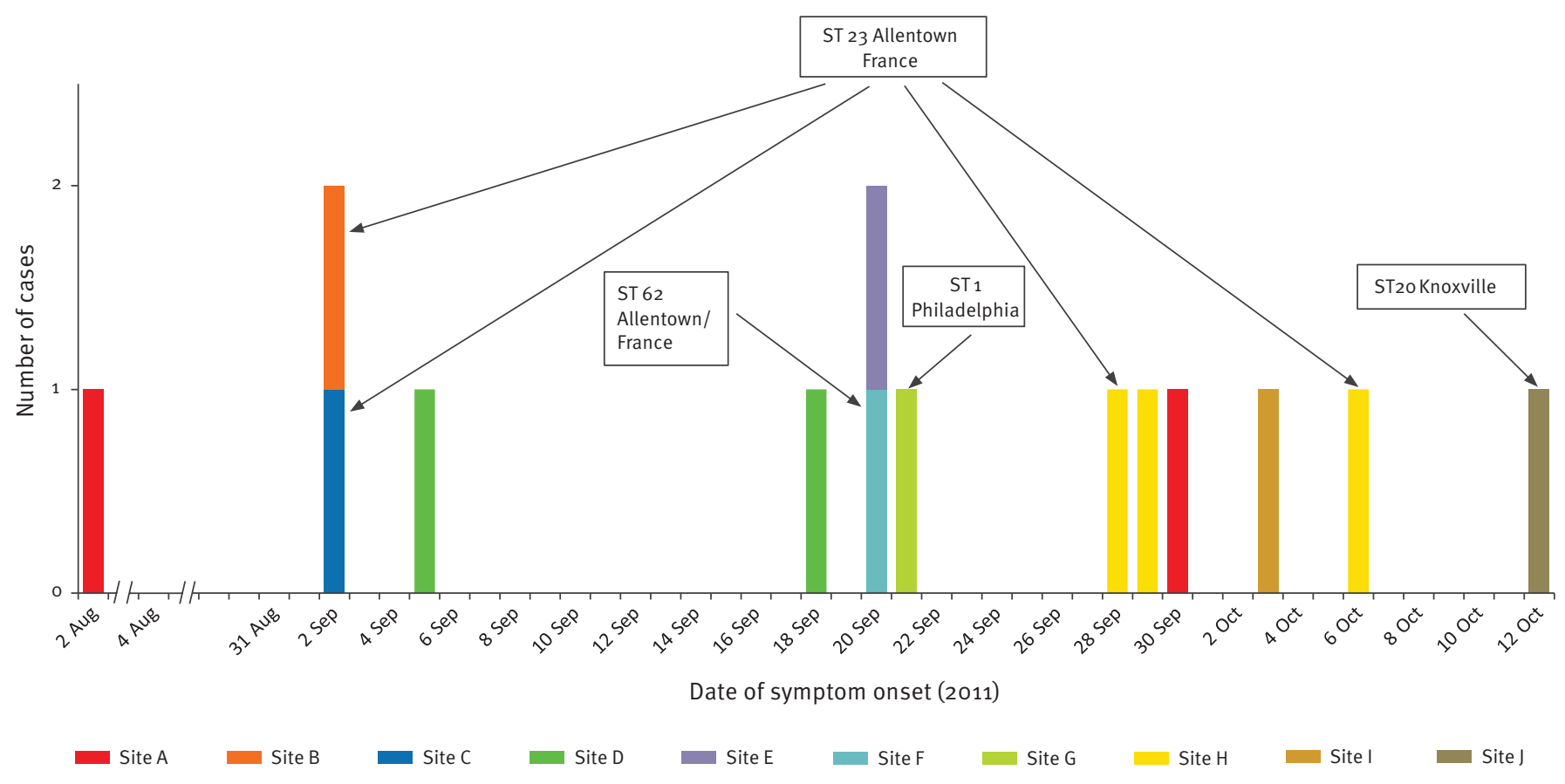

ST: sequence type.

a All cases had been in Corfu up to 14 days before onset of symptoms. 
legionellae were not recovered from any of these. The environmental investigations undertaken by the Greek authorities highlighted deficiencies in the disinfection and maintenance of water systems of the accommodation sites in Corfu. Issues with water temperature control were also identified. Environmental samples were obtained from nine of the 10 accommodation sites although for one site sampling was confined to samples taken from an external water tank, the pool filter and a pool shower since the business was insolvent and access to the hotel rooms was not possible. Excluding this latter site, sampling revealed that $L$. pneumophila serogroup 1 was present in all but one accommodation site, often in association with other $L$. pneumophila serogroups or Legionella species. The source of positive samples and the number of positive samples are indicated in the table. Samples from the airport and local town fountain were negative for legionellae.
All 14 cases were reported as L. pneumophila urinary antigen positive and samples from 13 of these were submitted to RSIL for confirmation. All 13 were confirmed as positive for $L$. pneumophila serogroup 1 $\mathrm{mAb}_{3} / 1+\mathrm{ve}$ antigen. Sputum samples were requested from all the patients but were received from only nine: legionellae were grown from seven of these, the remaining two were both culture and $L$. pneumophila PCR negative. The typing results of both the clinical and environmental samples submitted by the Greek authorities to RSIL are summarised in the table. In four instances, clinical isolates and corresponding environmental isolates were available for comparison, and in two of these (Sites C and G) they were indistinguishable, having the same mononclonal antibody (mAb) subgroup and sequence type. Furthermore, for four of the five patients who stayed in Sites A, D and F,

\section{TABLE}

Results from the typing of environmental and clinical samples of England and Wales cases of Legionnaires' disease associated with travel to Corfu, Greece, August-October 2011

\begin{tabular}{|c|c|c|c|c|c|}
\hline Accommodation & $\begin{array}{l}\text { Number of } \\
\text { positive } \\
\text { samples }\end{array}$ & $\begin{array}{c}\text { Sources of positive } \\
\text { environmental samples } \\
\text { submitted by Greek } \\
\text { laboratories }\end{array}$ & Environmental isolates recovered & Patient & Clinical microbiology result \\
\hline \multirow{2}{*}{ Site $A^{a}$} & \multirow{2}{*}{$7 / 9$} & \multirow{2}{*}{$\begin{array}{c}\text { Cold and hot water } \\
\text { shower, swimming pool } \\
\text { shower }\end{array}$} & \multirow{2}{*}{$\begin{array}{c}\text { L.p Sgp1, mAb ‘Oxford/OLDA’, ST1 } \\
\text { L.p Sgp1, mAb ‘Philadelphia’, ST1 } \\
\text { L.p Sgp3, ST388 }\end{array}$} & $1^{\mathrm{a}}$ & L.p Sgp1, $\mathrm{mAb}_{3} / 1+\mathrm{ve}$ \\
\hline & & & & $11^{\mathrm{a}}$ & L.p Sgp1, mAb3/1+ve \\
\hline Site B & $2 / 12$ & Cold water shower & L.p Sgp1, mAb ‘Oxford/OLDA', ST1 & 2 & $\begin{array}{l}\text { L.p Sgp1, mAb ‘Allentown/ } \\
\text { France', ST23 }\end{array}$ \\
\hline Site $C^{b}$ & $1 / 4$ & Hot water shower & L.p Sgp1, mAb 'Allentown/France', ST23 & $3^{b}$ & $\begin{array}{l}\text { L.p Sgp1, mAb 'Allentown/ } \\
\text { France', ST23 }\end{array}$ \\
\hline \multirow[b]{2}{*}{ Site D } & \multirow[b]{2}{*}{$5 / 20$} & \multirow{2}{*}{$\begin{array}{l}\text { Cold and hot water } \\
\text { shower }\end{array}$} & \multirow{2}{*}{$\begin{array}{c}\text { L.p Sgp1, mAb 'Allentown/France', ST23 } \\
\text { L.p Sgp6, ST461 } \\
\text { Legionella anisa }\end{array}$} & $4^{a}$ & L.p Sgp1, mAb3/1+ve \\
\hline & & & & $5^{\mathrm{a}}$ & L.p Sgp1, mAb3/1+ve \\
\hline Site $\mathrm{E}$ & $4 / 8$ & Hot water shower & $\begin{array}{c}\text { L.p Sgp1, mAb ‘Oxford/OLDA’, ST1 } \\
\text { L.p Sgp6, ST461 }\end{array}$ & 6 & $\begin{array}{l}\text { L.p Sgp1, mAb 'Allentown/ } \\
\text { France', ST62 }\end{array}$ \\
\hline Site $\mathrm{F}^{\mathrm{a}}$ & $11 / 19$ & $\begin{array}{l}\text { Cold and hot water } \\
\text { shower }\end{array}$ & $\begin{array}{c}\text { L.p Sgp1, mAb ‘Benidorm’, ST42 } \\
\text { L.p Sgp6, ST126o } \\
\text { L.p Sgp10, NT }\end{array}$ & $7^{\mathrm{a}}$ & L.p Sgp1, mAb3/1+ve \\
\hline Site $G^{b}$ & $6 / 8$ & $\begin{array}{l}\text { Cold and hot water } \\
\text { shower }\end{array}$ & $\begin{array}{l}\text { L.p Sgp1, mAb ‘Philadelphia’, ST1 } \\
\text { L.p Sgp6, NT }\end{array}$ & $8^{\mathrm{b}}$ & $\begin{array}{l}\text { L.p Sgp1, mAb } \\
\text { 'Philadelphia', ST1 }\end{array}$ \\
\hline \multirow{3}{*}{ Site $\mathrm{H}^{c}$} & \multirow{3}{*}{$0 / 3$} & \multirow{3}{*}{ None identified } & \multirow{3}{*}{$\begin{array}{l}\text { Legionellae not recovered from } \\
\text { external samples }\end{array}$} & 9 & $\begin{array}{l}\text { L.p Sgp1, mAb ‘Allentown/ } \\
\text { France', ST23 }\end{array}$ \\
\hline & & & & 10 & $\begin{array}{l}\text { No samples submitted to } \\
\text { Respiratory and Systemic } \\
\text { Infections Laboratory }\end{array}$ \\
\hline & & & & 13 & $\begin{array}{l}\text { L.p Sgp1, mAb ‘Allentown/ } \\
\text { France', ST23 }\end{array}$ \\
\hline Site I & $5 / 9$ & $\begin{array}{c}\text { Cold and hot water } \\
\text { shower, swimming pool }\end{array}$ & $\begin{array}{c}\text { L.p Sgp1, mAb 'Oxford/OLDA', ST1 } \\
\text { L.p Sgp3, NT }\end{array}$ & 12 & L.p Sgp1, mAb3/1+ve \\
\hline Site $J$ & $0 / 12$ & None identified & $\begin{array}{c}\text { Legionellae not recovered from any } \\
\text { samples }^{d}\end{array}$ & 14 & $\begin{array}{l}\text { L.p Sgp1, mAb 'Knoxville’, } \\
\text { ST20 }\end{array}$ \\
\hline
\end{tabular}

NT: not tested.

\footnotetext{
a No clinical isolate available for typing but the urinary antigen result is consistent with infection being due to an isolate recovered from the site.

b Clinical and environmental isolates match.

c No samples could be obtained from hotel rooms but three swabs were collected from the pool and water tank outside the building.

d Sampling was not performed according to protocol as the hotel was closed due to foreclosure procedures.
} 
although no clinical isolates were obtained, the RSIL urinary antigen assay result confirmed that they were all infected with L. pneumophila serogroup 1 strains expressing the $\mathrm{mAb}_{3} / 1$ epitope and among the environmental isolates recovered from each of these sites, there were strains that carried the same epitope (i.e. mAb Philadelphia, Allentown/France and Benidorm). Given that $\mathrm{mAb}_{3} / 1+\mathrm{ve}$ strains are generally uncommon in the environment [16], these data are consistent with, and supportive of the view that these accommodation sites were the source of these patients' infection.

\section{Control measures}

In response to the outbreak, the HCDCP issued guidelines to all health professionals in the region underlining the importance of early recognition, prompt diagnosis, timely management and notification of LD. The Greek authorities started a communication campaign aimed at providing information on the use of effective measures to prevent legionellosis on all Greek islands at the beginning of the 2012 tourist season. Communication material has been forwarded to Hotel Associations and other tourist accommodation providers and information seminars for these groups were organised on several islands.

In addition to the communication campaign, all regional public health laboratories, in collaboration with local public health authorities, have been conducting risk assessments and environmental sampling in a representative number of hotels in touristic areas of Greece, for example, Crete, Halkidiki, Skiathos and Corfu.

Along with environmental sampling, a risk assessment for each accommodation site was carried out in accordance with the European Working Group for Legionella Infections (EWGLI) guidelines and recommendations made on control measures to be taken [18].

\section{Conclusions}

Historically, of all the clusters identified in Greece between 1980 and 2010, 12 occurred in different accommodation sites in Corfu Island and involved between two and four cases of LD in residents from England and Wales. There were no environmental samples for any of the 12 clusters, but two of the historic sites were involved in the 2011 cluster of cases. This paper highlights the improvement in reporting environmental samples to the HPA national surveillance system and the benefits of collaborative working between European countries.

An interesting observation made early on in this investigation was the absence of cases reported in residents outside England and Wales. We would have expected to have seen more cases in residents from other countries visiting the island or perhaps among the local population. ELDSNet alerted all collaborating countries of the increase in case numbers and requested immediate submission of any cases associated with travel to Greece; however, no cases were reported. There is no evidence or reason to believe that travellers from England and Wales to Corfu Island are more susceptible to LD than travellers from any other country. Therefore, the reason behind this difference may be case ascertainment between health systems of other countries and England and Wales.

It is also important to note that only one death was associated with this incident. A plausible reason for this is that not all cases had clinically relevant comorbidities. In addition, increased awareness of the disease as a result of media interest may have altered clinical practice resulting in improved clinical outcome.

Given the high number of cases over a short period of time, initial concerns focused on the possibility of a point-source outbreak. The results of laboratory typing, however, indicated that simultaneous clusters of disease were occurring, as opposed to a common source outbreak. In most similar investigations few clinical isolates, few environmental isolates, or few of both, are available for comparison and this restricts the ability of investigators to detect multiple sources [19]. In this investigation we obtained clinical isolates from over $50 \%$ of cases and environmental samples from almost all potential sources. This high rate allowed us to obtain very strong evidence of the source for two cases and good, albeit indirect, evidence for a further five cases. This investigation illustrates both the value of subtyping in the corroboration of environmental results with clinical results, and the importance of obtaining sputum samples from patients in the context of an investigation. In six of the accommodation sites, multiple strains of L. pneumophila were recovered from the environment. While this is not an uncommon finding, it does illustrate that unless extensive environmental sampling, followed by characterisation of multiple isolates, is undertaken from potential sources, the infecting strain could easily be missed.

As the incident occurred during late summer and early autumn, the temperate weather conditions of that period may have encouraged the proliferation of the Legionella bacteria in water [20]. In combination with the lack of disinfection regimes in the accommodation sites, this may have been the underlying cause of the incident. All accommodation sites sampled were positive for Legionella indicating that, in general, standards for preventing Legionella colonisation were not adequate. It is therefore imperative that steps are taken to educate, support and inform all those working in the tourism industry about how to reduce the risk of Legionella infection, in particular during the summer season.

It is hoped that the communications campaign initiated by the Greek authorities will succeed in raising awareness. If it is demonstrated to have a positive impact on the number of cases of travel-associated Legionnaires' disease, there may be added value in further annual campaigns in reducing the burden of this infection 


\section{Acknowledgments}

KEDY (Central Public Health Laboratory, Vari-Attica, Greece): Anastasia Flountzi, Athanasios Mantas,

Thomais Koutsiomani, and Anastasios Katsoulis

PEDY (Regional Public Health Laboratory, Thessaly, Greece): Anna Katsiaflagka, Vasilis Nakoulas and Dimitris Gagktzis

KEELPNO (Hellenic Center for Disease Control and Prevention): Anastasia Andreopoulou, Ourania Kalkouni, Agoritsa Baka, Maria Pantelikizi

Corfu Public Health Authorities:

Kyriakos Katsoras, Ioannis Liggas, and Georgios Naoum.

\section{References}

1. The National Archives. The Health Protection (Notification) Regulations 2010. HM Government. [Accessed 24 Jul 2012]. Available from: http://www.legislation.gov.uk/uksi/2010/659/ contents/made

2. European Centre for Disease Prevention and Control (ECDC). Health topics. Legionellosis. Stockholm: ECDC. [Accessed 24 Jul 2012]. Available from: http://ecdc.europa.eu/en/ healthtopics/legionnaires_disease/pages/index.aspx

3. Fields BS, Benson RF, Besser RE. Legionella and Legionnaires' disease: 25 years of investigation. Clin Microbiol Rev. 2002;15(3):506-26.

4. Dondero TJ, Rendtorff RC, Mallison GF, Weeks RM, Levy JS, Wong EW. An outbreak of Legionnaires' disease associated with a contaminated air-conditioning cooling tower. $\mathrm{N} \mathrm{Enlg}$ Med. 1980;302(7):365-70.

5. Campese C, Roche D, Clément C, Fierobe F, Jarraud S, de Waelle $P$, et al. Cluster of Legionnaires' disease associated with a public whirlpool spa, France, April - May 2010. Euro Surveill. 2010;15(26):pii=19602. Available from: http://www. eurosurveillance.org/ViewArticle.aspx?Articleld $=19602$

6. Foster K, Gorton R, Waller J. Outbreak of legionellosis associated with a spa pool, United Kingdom. Euro Surveill. 2006;11(38): pii=3053. Available from: http://www. eurosurveillance.org/ViewArticle.aspx?Articleld=3053

7. Hilbi H, Jarraud S, Hartland E, Buchrieser C. Update on Legionnaires' disease: pathogenesis, epidemiology, detection and control. Mol Microbiol. 2010;76(1):1-11

8. Gaia V, Fry NK, Harrison TG, Peduzzi R. Sequence-based typing of Legionella pneumophila serogroup 1 offers the potential for true portability in legionellosis outbreak investigation. J Clin Microbiol. 2003;41(7):2932-9.

9. Mentasti M, Fry NK, Afshar B, Palepou-Foxley C, Naik FC, Harrison TG. Application of Legionella pneumophila specific quantitative real-time PCR combined with direct amplification and sequence-based typing in the diagnosis and epidemiological investigation of Legionnaires' disease. Eur J Clin Microbiol Infect Dis. 2012;31(8):2017-28.

10. European Centre for Disease Prevention and Control (ECDC). Annual Epidemiological Report 2011. Reporting on 2009 Surveillance Data and 2010 Epidemic Intelligence Data. Stockholm: ECDC; 2011. Available from: http://ecdc.europa. eu/en/publications/Publications/1111_SUR_Annual_ Epidemiological_Report_on_Communicable_Diseases_in_ Europe.pdf

11. Office for National Statistics (ONS). Overseas Travel and Tourism, Quarter 3 2011. Newport: ONS. 12 Jan 2012. Available from: http://www.ons.gov.uk/ons/publications/re-referencetables.html?edition $=\mathrm{tcm} \% 3 \mathrm{~A} 77-250721$

12. Health protection Agency (HPA). National Surveillance Scheme for Legionnaires' Disease. London: HPA. [Accessed 24 Jul 2012]. Available from: http://www.hpa.org.uk/web/ HPAweb\&HPAwebStandard/Page/1204186210339

13. Health Protection Agency (HPA). National Enhanced Surveillance England and Wales. London: HPA. [Accessed 24 Jul 2012]. Available from: http://www.hpa.org.uk/webc/ HPAwebFile/HPAweb_C/1274088015310

14. European Centre for Disease Prevention and Control (ECDC). European Legionnaires' Disease Surveillance Network (ELDSNet). Stockholm: ECDC. [Accessed 24 Jul]. Available from: http://ecdc.europa.eu/en/activities/surveillance/eldsnet/ pages/index.aspx
15. Birtles RJ, Harrison TG, Samuel D, Taylor AG. Evaluation of urinary antigen ELISA for diagnosing Legionella pneumophila serogroup 1 infection. J Clin Pathol 1990;43(8):685-90.

16. Helbig JH, Bernander S, Castellani Pastoris M, Etienne J, Gaia $\mathrm{V}$, Lauwers S, et al. Pan-European study on culture-proven Legionnaires' disease: distribution of Legionella pneumophila serogroups and monoclonal subgroups. Eur J Clin Microbiol Infect Dis. 2002;21(10):710-6.

17. Dennis J. Isolation of legionellae from environmental samples. In Harrison TG, Taylor AG. (Eds). A laboratory manual for Legionella. Chichester: J Wiley \& Son, 1988.

18. The European Surveillance Scheme for Travel Associated Legionnaires' Disease and the European Working Group for Legionella Infections. European Guidelines for Control and Prevention of Travel Associated Legionnaires' Disease. [Accessed 24 Jul 2012]. Available from: http://www.hpa.org. uk/webc/HPAwebFile/HPAweb_C/1274093149925

19. Rota MC, Scaturro M, Fontana S, Foroni M, Boschetto G, Trentin L, et al. Cluster of travel-associated Legionnaires' disease in Lazise, Italy, July to August 2011 . Euro Surveill. 2011;16(40):pii=19982. Available from: http://www. eurosurveillance.org/ViewArticle.aspx?Articleld=19982

20. Wadowsky RM, Wolford R, McNamara AM, Yee RB. Effect of temperature, $\mathrm{pH}$, and oxygen level on the multiplication of naturally occurring Legionella pneumophila in potable water. Appl Environ Microbiol. 1985; 49(5):1197-205. 